\title{
AN INVESTIGATION OF THE MECHANISM OF IGA/SCC OF ALLOY 600 IN CORROSION ACCELERATING HEATED CREVICE ENVIRONMENTS
}

\author{
NUCLEAR ENERGY RESEARCH INITIATIVE (NERI) PROGRAM \\ DE-FG03-99SF21921 \\ TECHNICAL PROGRESS REPORT \\ Fourth Quarter \\ Principal Investigator: \\ Dr. Jesse Lumsden \\ Rockwell Science Center \\ 1049 Camino dos Rios \\ RECEIVED \\ OCT 022000 \\ OS TI \\ Thousand Oaks, CA 91360 \\ E-Mail: jblumsden@rsc.rockwell.com
}

This program focuses on understanding mechanisms causing corrosion damage to steam generator tubes in a pressurized water reactor (PWR). The crevice formed by the tube/tube support plate (T/TSP) intersection in a PWR steam generator is a concentration site for nonvolatile impurities (referred to as hideout) from the steam generator water. The restricted mass transport in the small crevice volume prevents the species, which concentrate during the generation of steam, from quickly dispersing into the bulk water. The concentrated solutions in crevices have been a contributing cause of several forms of corrosion of steam generator tubes including intergranular attack/stress corrosion cracking (IGA/SCC), pitting, and wastage (general corrosion of the tube). The rate and type of corrosion are dependent on $\mathrm{pH}$, specific anions, and the electrochemical potential (ECP). A key variable is the ECP since the type and kinetics of corrosion processes are determined by the potential.

Increases in water purity, reductions in oxygen ingress, the use of buffers such as boric acid, and injecting hydrazine to maintain reducing conditions have been generally successful in controlling all forms of corrosion except IGA/SCC. Tube damage by IGA/SCC continues to result in plant shutdowns due to leakage, extended 


\section{DISCLAIMER}

This report was prepared as an account of work sponsored by an agency of the United States Government. Neither the United States Government nor any agency thereof, nor any of their employees, make any warranty, express or implied, or assumes any legal liability or responsibility for the accuracy, completeness, or usefulness of any information, apparatus, product, or process disclosed, or represents that its use would not infringe privately owned rights. Reference herein to any specific commercial product, process, or service by trade name, trademark, manufacturer, or otherwise does not necessarily constitute or imply its endorsement, recommendation, or favoring by the United States Government or any agency thereof. The views and opinions of authors expressed herein do not necessarily state or reflect those of the United States Government or any agency thereof. 


\section{DISCLAIMER}

Portions of this document may be illegible in electronic image products. Images are produced from the best available original document. 
outages for plugging large numbers of tubes, and replacement of steam generators.

The present strategy for mitigating IGA/SCC is based on the assumption that crack initiation and propagation rates depend on $\mathrm{pH}$ and the electrochemical potential. Laboratory data, using static autoclaves, show that IGA/SCC crack growth rates reach a minimum at $\mathrm{pH}$ 's between 5 and 9. Laboratory values for crack growth rates range over an order of magnitude at a given $\mathrm{pH}$. The lowest values of crack growth rates were generally obtained, in laboratory experience, when the ECP was lowered by deaeration, the highest values were obtained when the ECP was raised by significant amounts of dissolved oxygen in the test solutions or by applied ECP. Accordingly, all plants have adopted the practice of injecting hydrazine to maintain reducing conditions. Some plants are also adjusting the $\mathrm{Na} / \mathrm{Cl}$ ion ratio in the feedwater using a procedure called Molar Ratio Control. This procedure is used to control the crevice $\mathrm{pH}$ in the range of 5 to 9 . These measures have been successful in reducing the rate of increase in tubes affected by IGA/SCC in some plants; however, other plants using the same measures have experienced a rapid increase in IGA/SCC. The reason for this variability is not understood.

There are several uncertainties in the Molar Ratio Control/hydrazine approzch to controlling IGA/SCC. Since measurements of crevice chemistry and electrochemical potential (ECP) cannot be made in an operating steam generator, estimates are made using computer codes based on hypothesized processes believed to occur in crevices. Moreover, laboratory IGA/SCC data were obtained in static autoclaves using simulated crevice solutions. The IGA/SCC mechanism may be different under heat flux conditions, during which steam is being generated. Crevice chemistries are complex and $\mathrm{pH}$ may not be the important factor or the only important factor.

The objective of this program is to develop the understanding of the corrosion accelerating mechanisms, particularly IGA/SCC, in steam generator crevices. The important variables will be identified, including the relationship between bulk water chemistry and corrosion accelerating chemistries in a crevice. The approach uses an instrumented heated crevice, which is a replica of a PWR steam generator tube/TSP crevice. With the system operating at simulated steam generator thermal conditions, measurements are 
made of the chemical, electrochemical, and thermal conditions in the crevice. Damage to the tube due to IGA/SCC and other corrosion processes are monitored using electrochemical noise. Task 1: Modification of Heated Crevice for SCC and Electrochemical Noise Measurements.

\section{Task Status.}

The construction of the heated crevice with the capabilities of monitoring the crevice chemistry, the thermal conditions in the crevice, and SCC of the tube was completed the previous reporting period. Figure 1 is a photograph showing the complete layout. The autoclave containing the crevice is in the center of the photograph. Compressed $\mathrm{He}$ in the cylinder to the left of the autoclave is used to pressurize the tube. Water is pumped from the feed tank (located at the far left in the photograph) through the remainder of the water circuit by a high pressure pump. Before entering the autoclave, the water passes through a preheater. Water exits the system after passing through a condenser. The panel on the wall at the far right contains the circuits and controls for the band heaters on the autoclave.

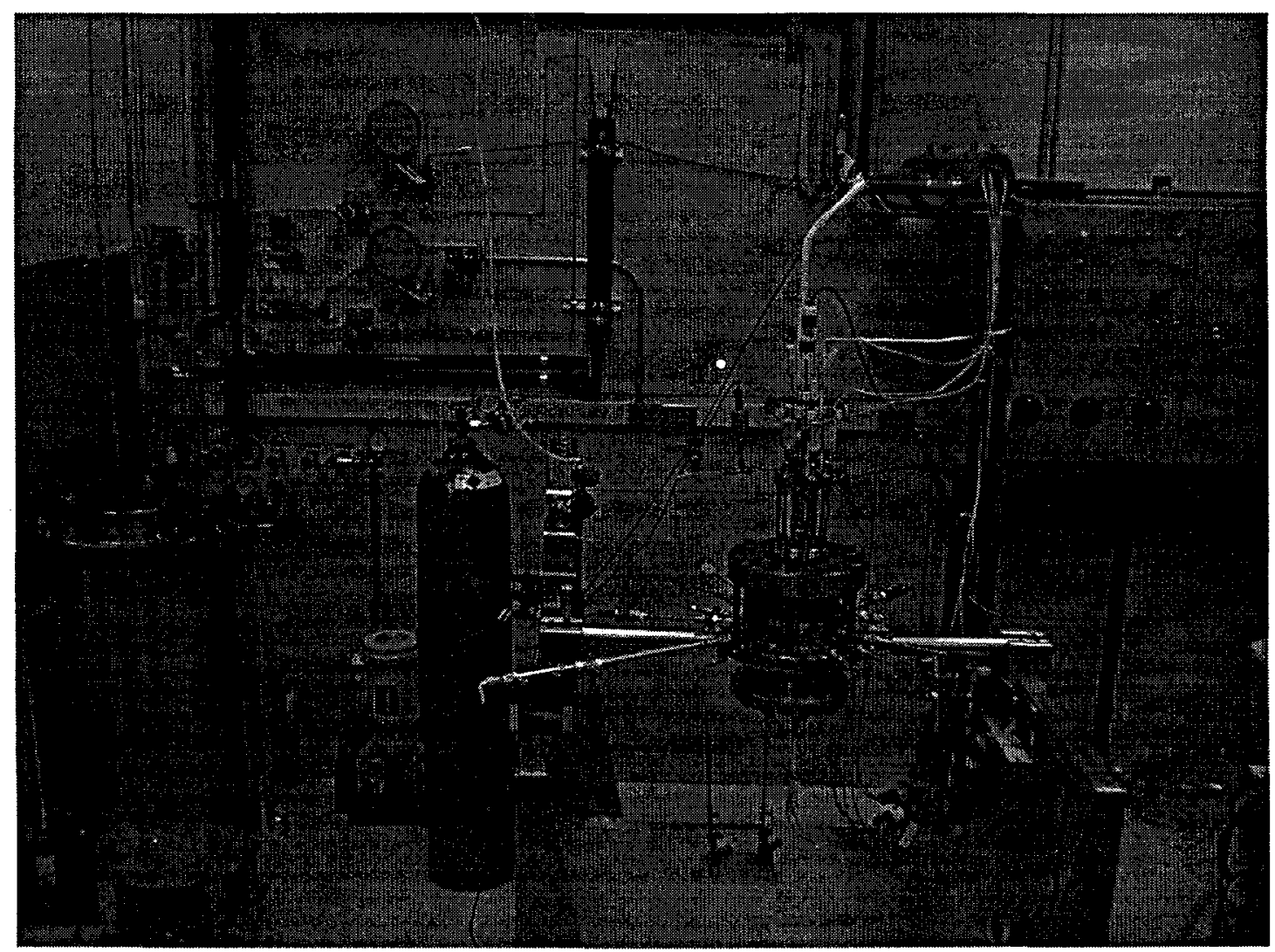


Figure 1. Photograph of the heated crevice system.

The effort during this quarter has been directed toward making the system operational and benchmarking the capabilities of the system. The system has performed within design parameters with the bulk water at $280^{\circ} \mathrm{C}$ and with the tube heater, simulating primary water, as high as $350^{\circ} \mathrm{C}$. The computerized data acquisition system continually monitors the wall thermocouples and the reference electrodes as designed. Solutions have been extracted from the crevice successfully for chemical analysis. All performance data indicate that the system will operate well within the planned operating parameters.

\section{Task 2: Evaluation of Electrochemical Noise}

Task Status: The initial work in this task has been directed toward evaluating the feasibility of using electrochemical noise to monitor the initiation and propagation of SCC in Alloy 600 exposed to the types of environments, which are planned for the heated crevice. The first SCC measurements in the heated crevice are being performed in a caustic crevice chemistry environment. Thus, static autoclave work has been using C-rings exposed to a $50 \% \mathrm{NaOH}$ solution having a 5\% hydrogen cover gas. Laboratory experience has found that SCC occurs when the electrochemical potential is between $150 \mathrm{mV}$ and $300 \mathrm{mV}$ above the corrosion potential in this type of environment. Current measurements have been made between two nominally identical C-rings, one of which is at open circuit and the other is polarized at $200 \mathrm{mV}$. One C-ring was stressed at $150 \%$ yield at the apex and the other was not stressed. The current was measured by connecting the two C-rings with a zero resistance ammeter using a Gamry ESA400 data acquisition unit. For comparison, the identical experiment was performed, in which both C-rings had no applied stress.

Figure 2 shows the current noise obtained from the couple in which one of the C-rings had an applied stress. The current noise from the couple, in which neither C-ring had an applied stress is shown in Figure 3. Clearly the couple with the stressed C-ring has regions where the peak-to-peak current transients exceed those from the couple with stressed C-rings by almost two orders of magnitude. The four specimens were contained in the same 
autoclave. When the C-rings were examined after the experiment, a through-wall, intergranular crack was found in the C-ring, which had been stressed at $150 \%$ yield stress. There were no cracks in the specimens, which were not stressed. Current transients are generated during SCC by the oxidation of the new surface created as a crack advances. An examination of the data from the couple with the stressed C-ring suggests that crack growth is discontinuous and occurred during four 5 or 10 hour intervals over the 2 day test period. An expanded time scale of the regions of rapid crack growth shows that the current in rich in structure.
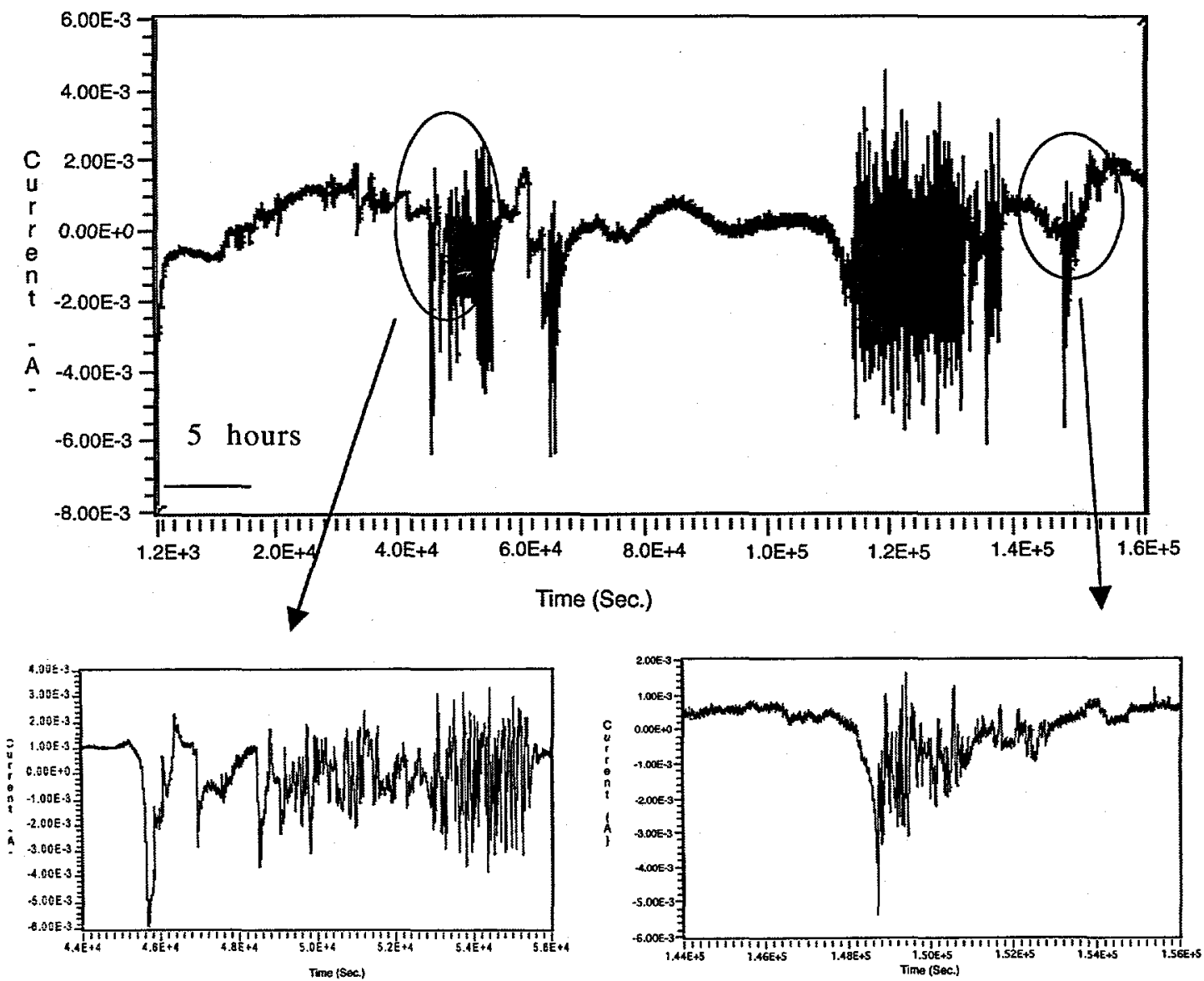

Figure 2. Current noise from a couple formed by an Alloy 600 $\mathrm{C}$-ring stressed at $150 \%$ yield and one with no applied stress. The environment was $50 \% \mathrm{NaOH}$ at $320^{\circ} \mathrm{C}$. 


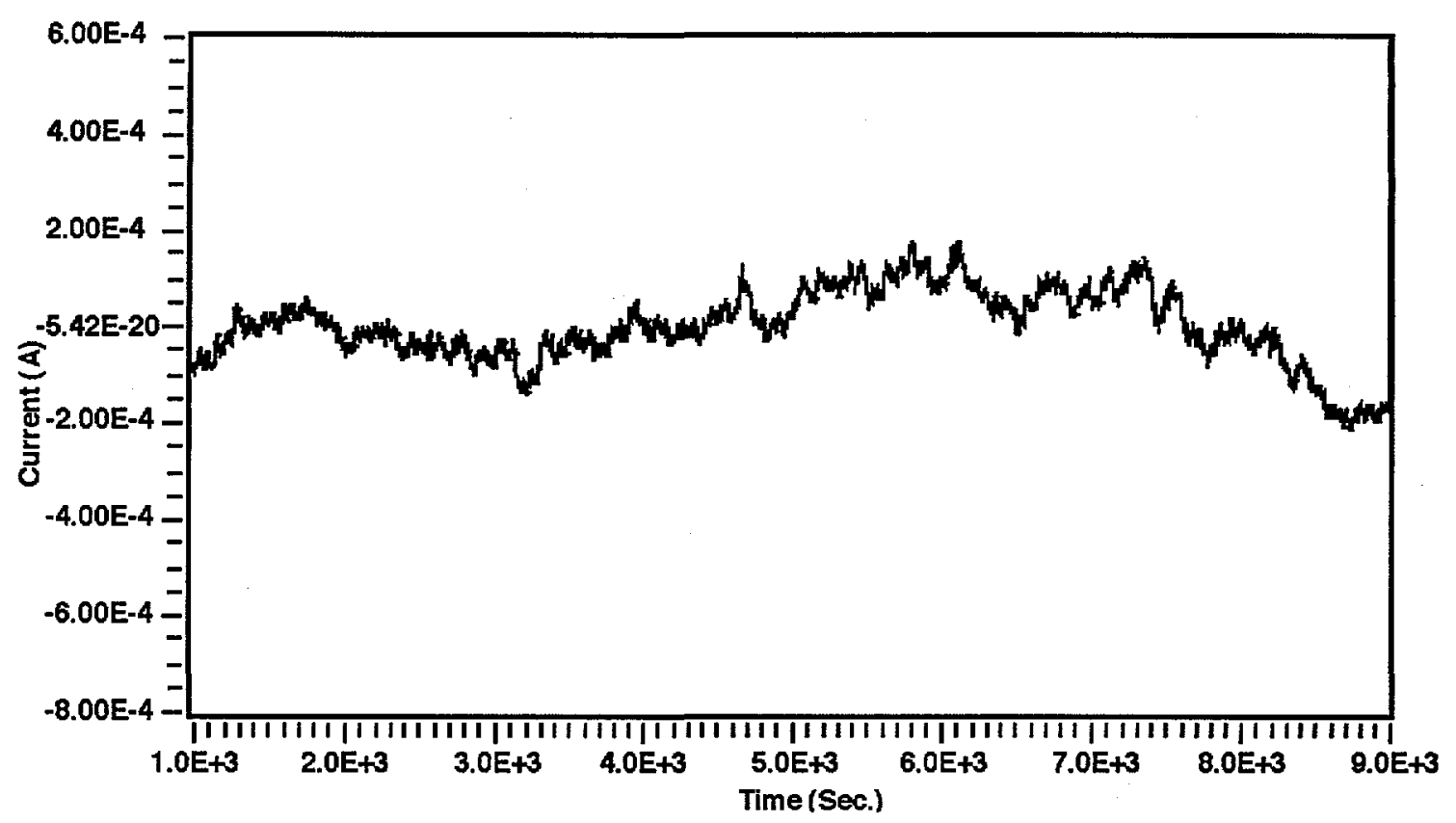

Figure 3. Current noise from a couple formed by an Alloy 600 C-ring, neither of which has an applied stress. The environment was $50 \% \mathrm{NaOH}$ at $320^{\circ} \mathrm{C}$. Note that the y-axis is expanded an order of magnitude compared to that in Figure 2.

The electrochemical noise system on the heated crevice has been made fully operational. The current noise is being monitored between the Alloy 600 tube and an Alloy 600 ring used to form the simulated T/TSP crevice. Potential noise is being monitored between the tube and a $\mathrm{Ni}$ rod pseudo reference electrode. Noise measurements are being made using a superheat of $50^{\circ} \mathrm{C}$ and a $280^{\circ} \mathrm{C}$ saturation temperature. The feedwater has $40 \mathrm{ppm} \mathrm{NaOH}$. The tube is pressurized at 2300 psi. These conditions will be our baseline conditions. Examples of the potential and current noise generated are shown in Figure 4 for a time record of 2250 seconds. A series of sharp potential and current perturbations are present extending over an order of magnitude over the background. The current and potential "spikes" occurred simultaneously, but had opposite polarity. These "spikes" did not occur when SCC conditions were removed (no superheat, tube not pressurized). 


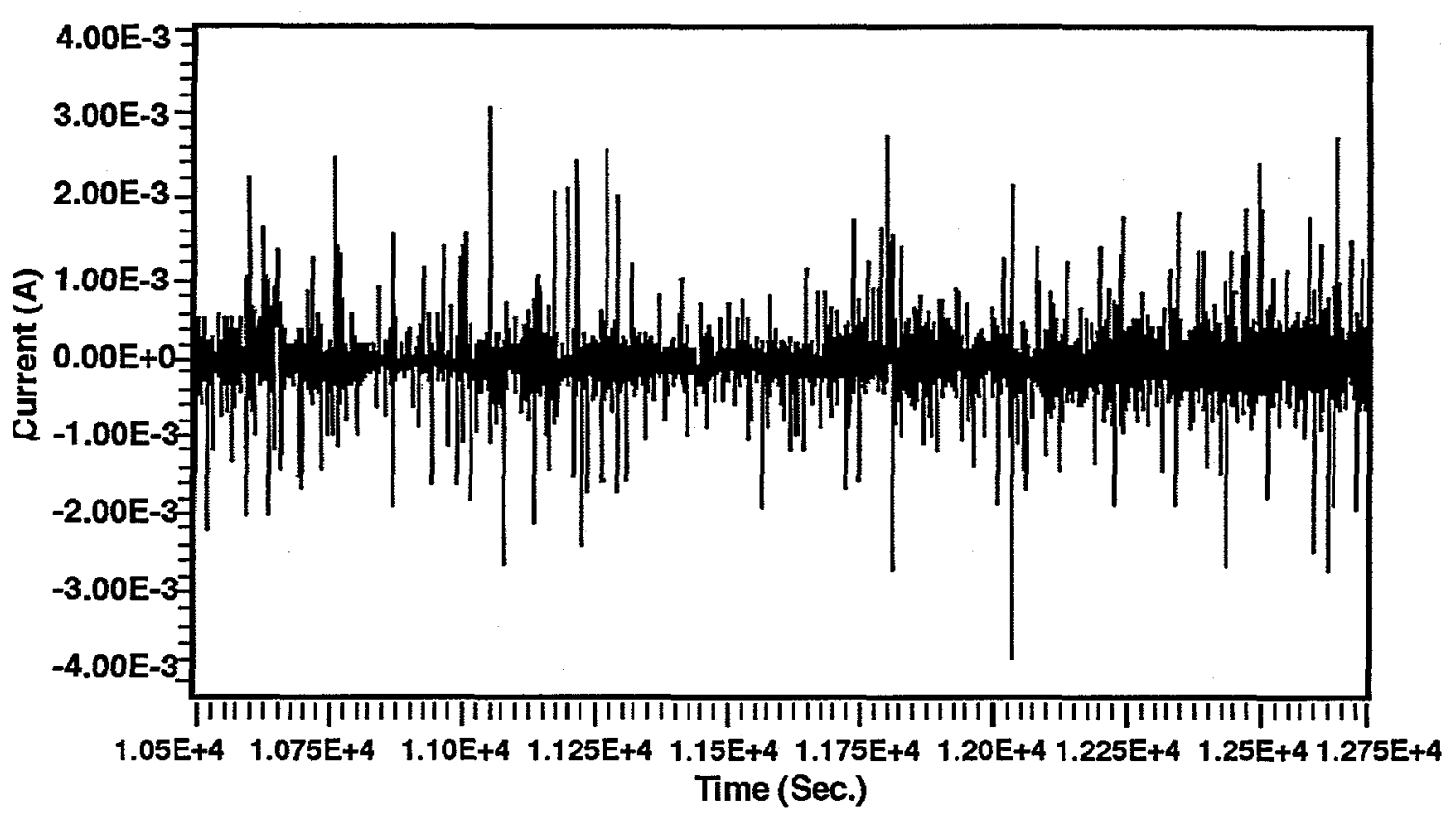

a)

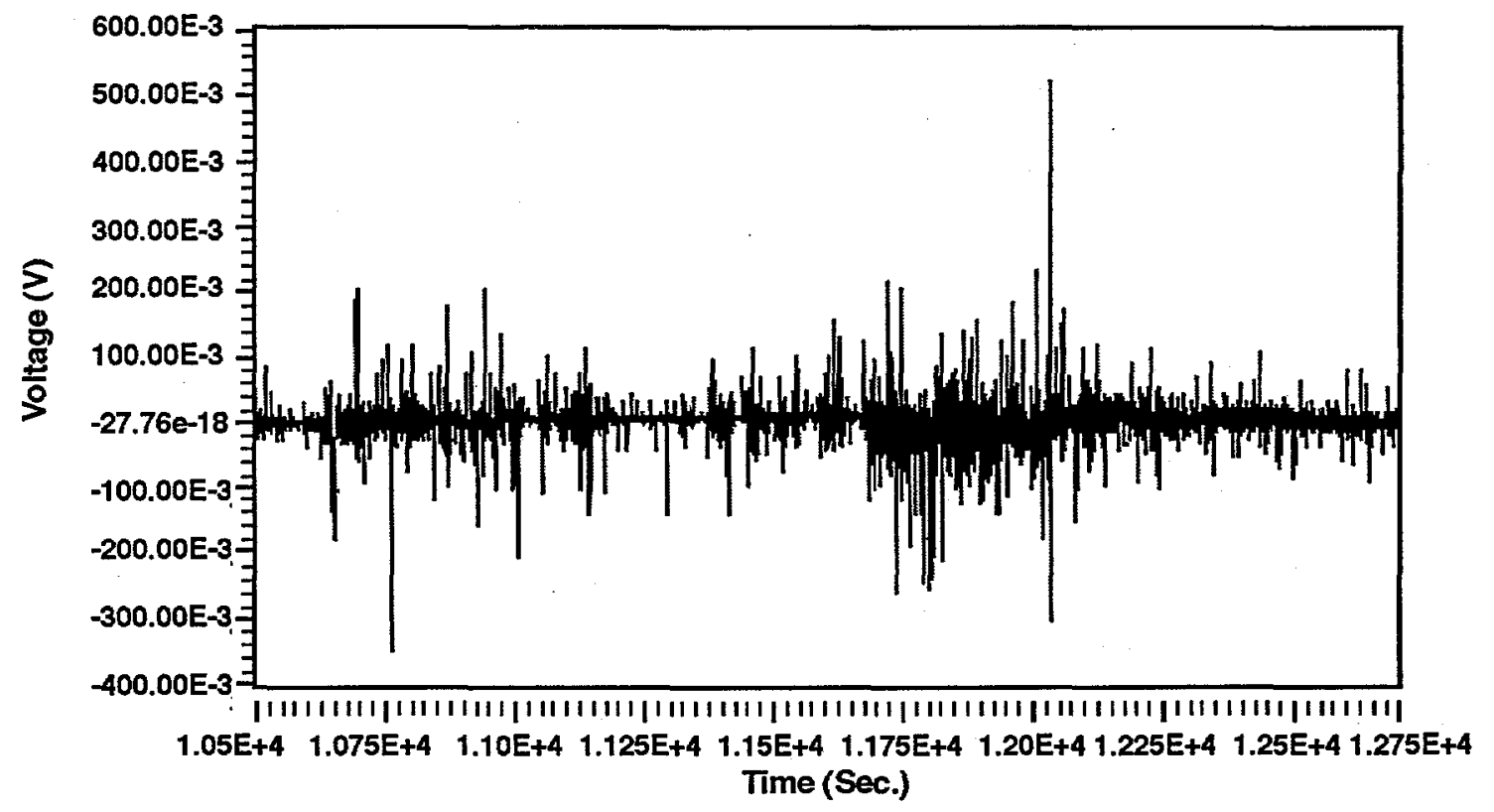

b)

Figure 4. Perturbation in current a) and potential b) noise during SCC in a pressurized Alloy 600 tube in the heated crevice. 


\section{MiLestones}

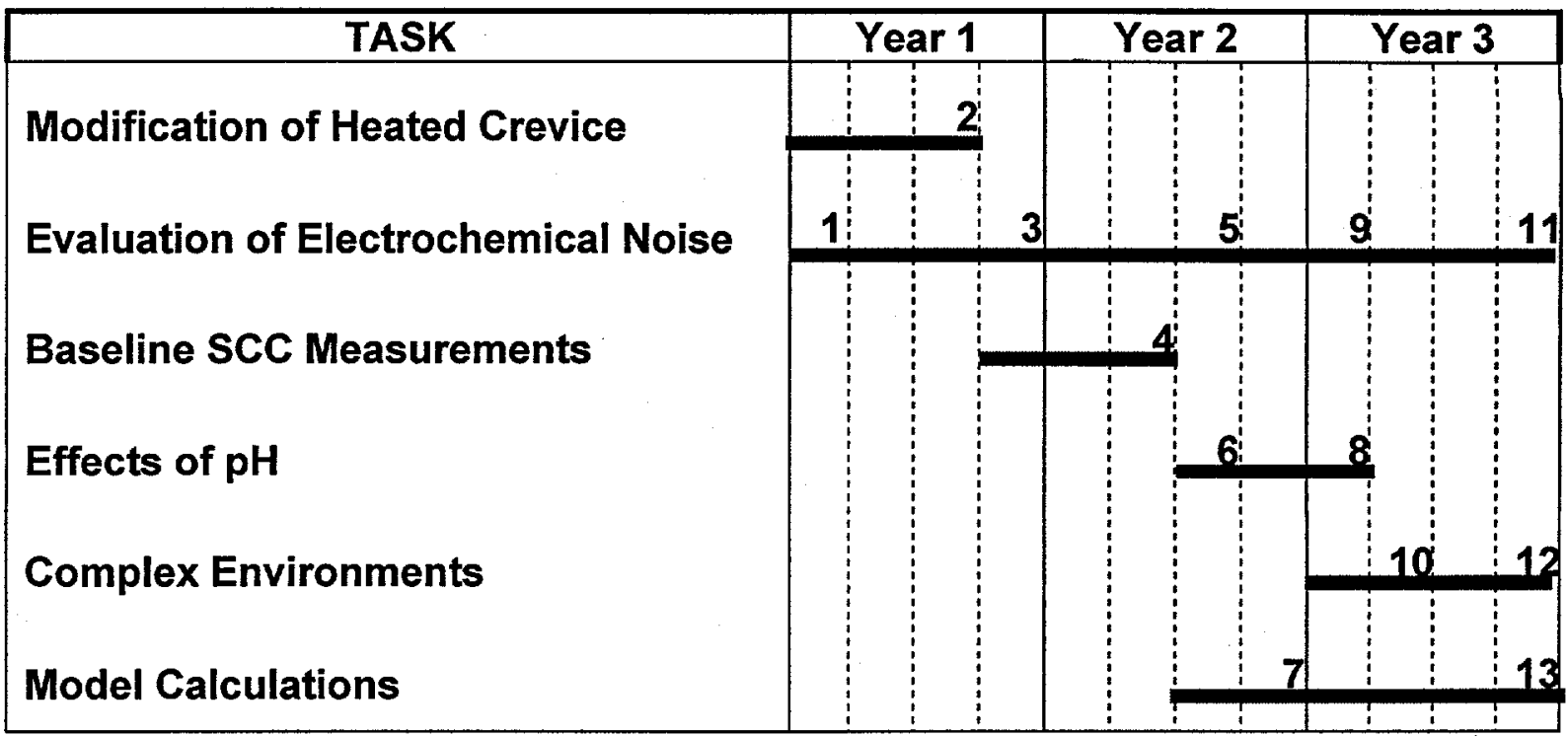

1. Complete design of electromechanical noise sensor. (Completed)

2. Complete construction of heated crevice for IGA/SCC and electrochemical noise measurements. (Completed)

3. Complete initial evaluation of SCC by electrochemical noise. (Completed)

4. Complete IGA/SCC reference measurements. (In Progress)

5. Complete analysis of electrochemical noise from reference conditions. (In Progress)

6. Complete IGA/SCC measurements in alkaline conditions.

7. Compare laboratory results with model calculations for alkaline conditions.

8. Evaluate effects of $\mathrm{pH}$ on IGA/SCC.

9. Evaluate $\mathrm{pH}$ effects on IGA/SCC initiation and propagation mechanism by electrochemical noise.

10. Make IGA/SCC measurements in hydrazine chemistries.

11. Evaluate affects of complex environments on IGA/SCC mechanism using electrochemical noise.

12. Determine if $\mathrm{pH}$ alone or other complex chemical variables control IGA/SCC.

13. Benchmark models for crevice chemistry and IGA/SCC. 